\title{
Cognitive phenotypes 1 month after ICU discharge in mechanically ventilated patients: a prospective observational cohort study
}

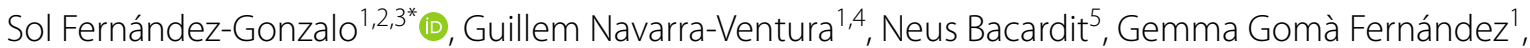
Candelaria de Haro ${ }^{1,4}$, Carles Subirà ${ }^{6}$, Josefina López-Aguilar ${ }^{1,4}$, Rudys Magrans ${ }^{7}$, Leonardo Sarlabous ${ }^{1}$, Jose Aquino Esperanza ${ }^{1,4,8}$, Mercè Jodar ${ }^{2,3,9}$, Montse Rué10,11 , Ana Ochagavía 1,4, Diego J. Palao 2,12,13,

Rafael Fernández ${ }^{4,6}$ and Lluís Blanch ${ }^{1,4,8}$

\begin{abstract}
Background: ICU patients undergoing invasive mechanical ventilation experience cognitive decline associated with their critical illness and its management. The early detection of different cognitive phenotypes might reveal the involvement of diverse pathophysiological mechanisms and help to clarify the role of the precipitating and predisposing factors. Our main objective is to identify cognitive phenotypes in critically ill survivors 1 month after ICU discharge using an unsupervised machine learning method, and to contrast them with the classical approach of cognitive impairment assessment. For descriptive purposes, precipitating and predisposing factors for cognitive impairment were explored.

Methods: A total of 156 mechanically ventilated critically ill patients from two medical/surgical ICUs were prospectively studied. Patients with previous cognitive impairment, neurological or psychiatric diagnosis were excluded. Clinical variables were registered during ICU stay, and 100 patients were cognitively assessed 1 month after ICU discharge. The unsupervised machine learning K-means clustering algorithm was applied to detect cognitive phenotypes. Exploratory analyses were used to study precipitating and predisposing factors for cognitive impairment.

Results: K-means testing identified three clusters (K) of patients with different cognitive phenotypes: K1 $(n=13)$, severe cognitive impairment in speed of processing (92\%) and executive function (85\%); K2 ( $n=33)$, moderate-tosevere deficits in learning-memory (55\%), memory retrieval (67\%), speed of processing (36.4\%) and executive function (33.3\%); and K3 $(n=46)$, normal cognitive profile in $89 \%$ of patients. Using the classical approach, moderate-tosevere cognitive decline was recorded in $47 \%$ of patients, while the K-means method accurately classified $85.9 \%$. The descriptive analysis showed significant differences in days $(p=0.016)$ and doses $(p=0.039)$ with opioid treatment in K1 vs. K2 and K3. In K2, there were more women, patients were older and had more comorbidities $(p=0.001)$ than in $\mathrm{K} 1$ or K3. Cognitive reserve was significantly $(p=0.001)$ higher in $\mathrm{K} 3$ than in $\mathrm{K} 1$ or K2.
\end{abstract}

Conclusion: One month after ICU discharge, three groups of patients with different cognitive phenotypes were identified through an unsupervised machine learning method. This novel approach improved the classical classification

*Correspondence: msfernandez@tauli.cat

${ }^{1}$ Critical Care Center, Parc Taulí Hospital Universitari, Fundació- I3PT, UAB,

Sabadell, Spain

Full list of author information is available at the end of the article permits use, sharing, adaptation, distribution and reproduction in any medium or format, as long as you give appropriate credit to the original author(s) and the source, provide a link to the Creative Commons licence, and indicate if changes were made. The images or other third party material in this article are included in the article's Creative Commons licence, unless indicated otherwise in a credit line to the material. If material is not included in the article's Creative Commons licence and your intended use is not permitted by statutory regulation or exceeds the permitted use, you will need to obtain permission directly from the copyright holder. To view a copy of this licence, visit http://creativecommons.org/licenses/by/4.0/. The Creative Commons Public Domain Dedication waiver (http://creativeco mmons.org/publicdomain/zero/1.0/) applies to the data made available in this article, unless otherwise stated in a credit line to the data. 
of cognitive impairment in ICU survivors. In the exploratory analysis, gender, age and the level of cognitive reserve emerged as relevant predisposing factors for cognitive impairment in ICU patients.

Trial registration: ClinicalTrials.gov Identifier:NCT02390024; March 17,2015.

Keywords: Cognition in ICU survivors, Neuropsychological profiles, Critical illness, Post-intensive care syndrome

\section{Introduction}

Cognitive impairment in critically ill survivors who have undergone invasive mechanical ventilation (MV) during the Intensive Care Unit (ICU) stay is a well-established health problem [1-11]. ICU admission is associated with a greater cognitive decline than general ward hospitalization [12], and the rate of dementia diagnosis after 3 years of follow-up has been reported to be higher in elderly ICU survivors than in the general population [13]. This cognitive decline affects the functional and socioeconomic status of ICU survivors and their families, and reduces their quality of life after ICU discharge [5, 1416]. Cognitive impairment may be as high as $64 \%$ in ICU survivors [17]. The domains most commonly affected are attention/concentration, memory and executive function [18].

The pathophysiological mechanisms that lead to cognitive dysfunction after critical illness are not well understood. Many precipitating or modifiable factors and predisposing or non-modifiable factors have been related to the short- and long-term cognitive deficit observed in ICU survivors [19]. Among precipitating factors such as MV [2, 20], length of ICU stay [9, 20], hypoxemia, hypoglycemia, hyperglycemia, fluctuations in serum glucose [20-22] and perceived stress levels during the ICU stay [23], the presence of delirium has shown the closest association with the cognitive impairment observed in ICU survivors [2, 3, 24-26]. Predisposing or non-modifiable factors have been less explored and in most studies have been considered as confounding factors. Nonetheless, older age, previous cognitive impairment and higher illness severity seem to increase the risk of developing cognitive dysfunction after ICU stay [18, 27]. The role of other individual predisposing factors has only rarely been studied in critical illness. One of these factors is cognitive reserve-that is, the ability of the brain to actively address brain dysfunction by using pre-existing cognitive processing approaches or by enlisting compensatory approaches [28]. Cognitive reserve may confer a better resilience to pathological brain changes; that is, people with higher cognitive reserve may be less vulnerable to neurophysiological insults such as the impact of critical illness and its management. Cognitive reserve may also be a target for rehabilitation programs when the brain insult has already occurred.
Most of the studies evaluating cognitive impairment in ICU survivors after MV have focused on global cognitive impairment, and little is known about the characterization of different phenotypes of alteration [12]. The early detection of distinct groups of patients regarding cognitive deficits might reveal the involvement of diverse pathophysiological mechanisms. Thus, the main objective of this study was to describe the cognitive phenotypes 1 month after ICU discharge in survivors of critical illness who had undergone MV during their ICU stay, using an unsupervised machine learning method. Two secondary objectives were also proposed. To warrant clinical interpretation of these results, we contrasted the cognitive phenotypes with the classical definition of cognitive impairment in critically ill patients established by Jackson et al. [7]. An exploratory analysis of the predisposing and precipitating factors (e.g., gender, medications, severity of illness and days with MV) of the cognitive dysfunction after critical care was also carried out.

\section{Material and methods}

\section{Sample and procedure}

This prospective cohort study enrolled patients from two medical/surgical ICUs from October 2015 until December 2017.

The study sample comprised critically ill adult patients ( $\geq 18$ years old) who had undergone invasive MV for at least $24 \mathrm{~h}$ during the ICU stay and had been enrolled during the first $48 \mathrm{~h}$ of MV. Exclusion criteria were: prior cognitive impairment or dementia, diagnosis of neurological disease, psychiatric disorder, sensory deficits (blindness or deafness), non-Spanish speaking and life expectancy $<3$ months. Previous neurological diagnosis (specifically of prior cognitive impairment or dementia) was checked in patients' clinical records and through interviews with their relatives. In patients $>60$ years old, preexisting cognitive impairment was assessed at ICU admission using the Spanish version of the Short Form of the Informant Questionnaire on Cognitive Decline in the Elderly (Short-IQCODE), filled in by relatives [29]. The cutoff point for exclusion on the Short-IQCODE was $>3.56$. Daily screening was performed by a critical care nurse. At enrollment, written informed consent was obtained from the patients or their authorized surrogates; if consent was initially obtained from a surrogate, 
it was subsequently obtained from the patient once s/he was deemed to be mentally competent.

\section{Measurements}

At inclusion, severity of illness was measured by the Acute Physiology and Chronic Health Evaluation (APACHE II) and level of comorbidity by the Charlson Comorbidity Index. Level of consciousness and presence of delirium were assessed daily using the Richmond Agitation Sedation Scale (RASS) and the Confusion Assessment Method for the ICU (CAM-ICU), respectively. Sequential Organ Failure Assessment (SOFA) was measured every day during ICU stay. Number of days receiving sedatives and opioids as well as the accumulated doses of sedation and analgesia were also recorded daily. All sequential data were recorded until ICU discharge or for a maximum of 30 days.

A complete and comprehensive neuropsychological assessment was administered 1 month after ICU discharge. Details of the neuropsychological battery are shown in Table 1 . The neuropsychological assessment was administered to all participants by an expert neuropsychologist during a single session lasting between 45 and $60 \mathrm{~min}$. Six cognitive indexes were calculated from the neuropsychological test scores: attention, learning and memory storage, memory retrieval, speed of processing, working memory and executive function.

\section{Statistical analysis}

Baseline demographics and clinical characteristics during the ICU stay were summarized using medians (IQR) for continuous variables and percentages for categorical variables. For the purposes of analysis, the variable diagnosis was operationalized in three categories (medical, surgical and polytrauma). Daily SOFA scores were summarized by a single value defined as the slope of the regression line on the first five SOFA scores. Length of delirium, MV, and sedative and opioid administration were adjusted for days of ICU. This data correction was performed by consensus between authors, on the assumption that data adjusted to the days of ICU can be a better reflection of ICU patients' true status. However, both variables (with and without adjustment) were initially considered in the univariate analysis. Total doses of opioids (morphine and fentanyl) and sedatives (midazolam, propofol and lorazepam) administered each day were recorded and converted to morphine and midazolam equivalents [30].

The cognitive reserve index was obtained for each patient based on two proxies: educational attainment, defined as the number of years in full-time formal education, and literacy, based on the corresponding intelligence quotient (IQ) score on the Spanish version of the National Adult Reading Test (NART) [31].

Raw scores of the cognitive tests were transformed into z-scores (mean $=0 ; S D= \pm 1$ ) using the normative population data offered by each test. Details of the cognitive index calculation are given in Additional file 1: Table S1.

Two different approaches were used for assessing cognitive impairment in the sample: the first a more classical approach based on the clinical definition of cognitive impairment, and the second a method based on statistical clustering algorithms.

In the classical approach, global cognitive impairment was considered when a patient scored $\geq 1.5$ SD below the mean on two or more of the six cognitive indexes, or else when a patient scored $\geq 2$ SD below the mean on one or more of the indexes. This clinical definition has been previously used in the literature [7] and is considered a strict, accurate description of cognitive deficit. The z-scores were also used to determine the level of cognitive deficit in each domain for every patient. Likewise, cognitive domain impairment was defined as moderate if the values of the index were $\geq 1.5 \mathrm{SD}$ below the mean and severe if the values were $\geq 2 \mathrm{SD}$ below the mean.

\section{Table 1 Cognitive tests used in the neuropsychological assessment battery}

\begin{tabular}{|c|c|}
\hline Cognitive domain & Tests \\
\hline Premorbid intelligence quotient (IQ) estimation & The National Adult Reading Test (NART)_-Spanish version- ${ }^{S .1}$ \\
\hline Verbal attention and working memory & Subtest of Digits from the Wechsler Adult Intelligence Scale version III (WAIS III) ${ }^{5.2}$ \\
\hline Visual attention and working memory & Subtest of Spatial Span from the Wechsler Memory Scale version III (WMS III) ${ }^{5.3}$ \\
\hline Learning, short- and long- term verbal memory & Rey Auditory Verbal Learning test ${ }^{5.4}$ \\
\hline Visual memory & Benton Visual Retention test ${ }^{5.5}$ \\
\hline Speed of processing & Subtest of Symbol Search (WAIS III) ${ }^{\text {S.2 }}$ \\
\hline $\begin{array}{l}\text { Speed of processing and Executive function (Automatic response } \\
\text { inhibition) }\end{array}$ & Stroop Color and Word test ${ }^{5.6}$ \\
\hline Speed of processing and Executive function (Flexibility) & Trail Making Test ${ }^{\text {s.7 }}$ \\
\hline Executive function (phonetic verbal fluency) & FAS $^{5.8}$ \\
\hline
\end{tabular}


The second approach aimed to find characteristic phenotypes and clusters of patients' cognitive decline through an unsupervised machine learning technique, the K-means clustering algorithm. K-means clustering is widely used in the data mining field to reveal naturally occurring patterns or groupings, without targeting a specific outcome [32, 33]. The clustering algorithm splits the observations (i.e., patients) into distinct and nonoverlapping clusters of cognitive phenotypes based on their cognitive score, without the need to establish an 'a priori' definition of cognitive deficit. The procedure was as follows: at each iteration, the algorithm computed the cluster centroids and each observation was assigned to the closest centroid. The Euclidean distance was used as the dissimilarity measure to minimize the within-cluster variation.

The Kruskal-Wallis test was used to analyze the differences between the $\mathrm{K}$ groups in the demographic and clinical data, and the Mann-Whitney $U$ test for group comparisons.

Only for exploratory purposes, the association between predisposing and/or precipitating factors and cognitive impairment was studied by binomial logistic regression analyses. Factors with a $p$ value $<0.2$ in the univariate analysis were included in the multivariable analysis. Modeling adjustments focused on obtaining a simplified model included all variables with $p$ values $<0.05$ or with clinical relevance for explaining the dependent variable.

\section{Results}

Four hundred and forty-two ICU patients were screened for inclusion. One hundred and fifty-six met the inclusion criteria, of whom 100 were cognitively assessed 1 month after ICU discharge. The final analysis was performed in 92 patients (Fig. 1). Mean age of the sample was 63.03 years (SD 12.78), and 57 participants were male (62\%). Further demographic and clinical data of the sample are shown in Table 2.

\section{Cognitive clusters of patients with the unsupervised machine learning K-means clustering algorithm approach}

The K-means test results showed three differential clusters of patients grouped regarding their characteristic cognitive phenotypes (13 patients in K1, 33 in $\mathrm{K} 2$ and 46 in K3) (Additional file 1: Fig. S1). The correlation analysis of the composite cognitive variables showed that all cognitive variables could be maintained in the K-means analysis (Additional file 1: Fig. S2).

In the K1 cluster, all patients showed global cognitive impairment: the most altered functions were speed of processing, which affected $93.23 \%$ of patients, and executive function, which affected $84.62 \%$. In the $\mathrm{K} 2$ cluster, $76 \%$ of patients showed global cognitive impairment:
$66.67 \%$ of participants showed alterations in memory retrieval, $54.5 \%$ in learning and memory storage, $36.36 \%$ in speed of processing and $33.33 \%$ in executive functions. In the K 3 cluster, only $11 \%$ of patients showed global cognitive impairment: $15.22 \%$ presented impaired executive function and $13.04 \%$ reduced speed of processing. Further details are given in Fig. 2 and in Additional file 1: Table S2.

Prevalence of global cognitive impairment and cognitive domain deficits using the classical approach: comparison with the K-means clustering algorithm approach

Using the classical approach, 43 patients (47\%) presented global cognitive impairment. When the six cognitive indexes were explored separately, the most commonly affected domain was speed of processing (33 patients, $36 \%$ ), followed by executive function ( 29 patients, $31 \%$ ), memory retrieval (23 patients, 25\%) and learning and memory storage ability (20 patients, 22\%). Attention and working memory were marginally affected, with one patient (1\%) showing a deficit in each domain. Note that the same patient could present deficits in different cognitive domains at the same time.

The results obtained with the two approaches were compared in order to warrant a feasible clinical interpretation of the groups obtained through the unsupervised machine learning approach. Compared to the classical definition of cognitive impairment, the K-means test classified most of the participants with cognitive impairment between the K1 and K2 groups; however, $89 \%$ of the participants in $\mathrm{K} 3$ did not present cognitive impairment. Thus, the K-means test failed to classify 13 patients (14.1\%) but correctly classified 79 (85.9\%) (Fig. 3).

\section{Analysis of predisposing and precipitating factors}

The descriptive analysis of the differences in the demographic and clinical variables between the three phenotypes showed that in $\mathrm{K} 2$ there were more women $(p=0.001)$, patients were older $(p<0.001)$ and had more comorbidities $(p<0.001)$ than in K1 or K3. Significant differences were also found in days $(p=0.016)$ and doses $(p=0.039)$ of opioid treatment in K1 than in K2 or K3. Cognitive reserve was significantly higher in K3 $(p=0.001)$ than in K1 or K2. Further details of the demographic and clinical data according to cluster group and percentage of diagnosis are shown in Table 3 and in Additional file 1: S3.

Since the K1 cluster contained only 13 patients, it was merged in a single group with the K2 cluster in order to explore the influence of predisposing and precipitating factors on global cognitive impairment by means of the binomial logistic regression model. The exploratory analysis was run in a group (K1+K2) in which most 
Patients screened for inclusion $(n=442)$

01.07.2015-14.12.2017

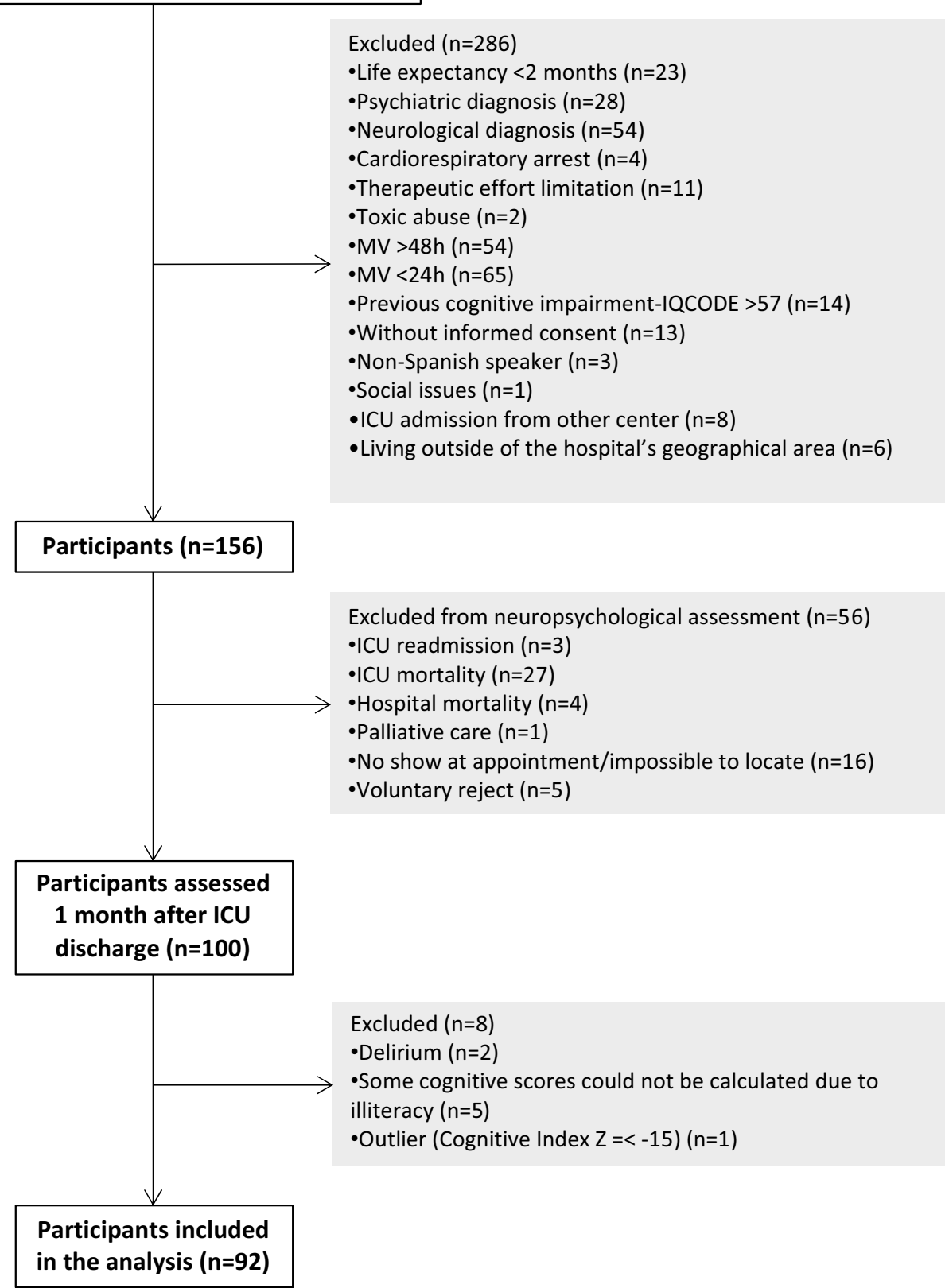

Fig. 1 Flowchart representing the distribution of the sample during the different phases of the study

participants were cognitively impaired versus the group (K3) in which most participants had a normal cognitive status. All variables from the univariate analyses with a $p$ value $<0.2$ (Additional file 1: Table S4) were included in a multivariable model. A reduced final multivariable model was run including the significant factors (gender, cognitive reserve and days with opioids) from the initial multivariable model and 'age' as a confounding factor. Age (OR 1.05; 95\% CI 1.00-1.01; $p=0.048$ ), gender (OR 2.81; 95\% CI 1.01-7.84; $p=0.048)$ and cognitive reserve (OR 0.37; 95\% CI 0.16-0.83; $p=0.016$ ) resulted statically significant, while days with opioids ratio presented a trend toward significance (OR 0.17; 95\% CI 0.03-1.08; $p=0.061$ ). Further details of the multivariable regression 


\begin{tabular}{lc}
$\begin{array}{l}\text { Table } 2 \text { Demographic } \\
\text { of the sample }\end{array}$ & and \\
\hline clinical & characteristics \\
\hline Age, yr & Total sample (N=92) \\
Female gender & $64(56-71)$ \\
Cognitive Reserve, z-scores & $35(38 \%)$ \\
Diagnosis: & $0.04(-0.32$ to 0.37$)$ \\
Medical & \\
Surgical & $74(80.4 \%)$ \\
Polytrauma & $10(10.9 \%)$ \\
APACHE II at ICU admission, points & $8(8.7 \%)$ \\
SOFA at ICU admission, points & $17(13-21)$ \\
SOFA slope & $7(5-9)$ \\
Charlson Index at ICU admission & $-0.9(-1.5$ to -0.2$)$ \\
Length of MV, days & $3(2-5)$ \\
MV days ratio & $6(4-10)$ \\
Length of delirium, days & $0.64(0.44-0.77)$ \\
Delirium ratio & $1(0-2)$ \\
Days with sedatives & $0.037(0-0.18)$ \\
Days with sedatives ratio & $4(2-7)$ \\
Accumulated dose of sedatives, Eq & $0.37(0.18-0.58)$ \\
Days with opioids & $3.31(0.95-8.79)$ \\
Days with opioids ratio & $4(2-7.75)$ \\
Accumulated dose of opioids, Eq & $0.37(0.20-0.62)$ \\
Length of ICU stay, days & $1.02(0.23-2.44)$ \\
Length of hospital stay, days & $10.50(8-16)$ \\
\hline & $16.00(10-34.5)$ \\
\hline &
\end{tabular}

Data are expressed as $\mathrm{n}(\%)$ or median (IQR), as appropriate

IOR interquartile range, APACHE Acute Physiology and Chronic Health Evaluation, SOFA Sequential Organ Failure Assessment, $M V$ mechanical ventilation, Eq equivalents

models are shown in Additional file 1: Table S5. The receiver operating characteristic (ROC) curve analysis of the final multivariable regression model is shown in Additional file 1: Figure S3.

\section{Discussion}

The main finding of this study is the characterization of three different cognitive phenotypes in critically ill-ventilated patients 1 month after ICU discharge using the unsupervised machine learning K-means clustering algorithm. The descriptive and exploratory analysis of factors revealed female gender and older age as potential risk factors for specific cognitive impairment, while cognitive reserve emerged as a protective factor against cognitive deficit.

This is the first study to report patterns of cognitive impairment after ICU discharge in mechanically ventilated patients based on an unsupervised machine learning algorithm clustering method. This novel approach allowed us to detect three different phenotypes in the ICU survivors based on the exploration of six cognitive domains, instead of the two categories (impaired vs. non-impaired) differentiated in the classical method by Jackson et al. [7]. Furthermore, in two of the three phenotypes, different levels and types of cognitive impairment were observed in the participants: while the K1 phenotype was characterized by severe alterations in speed of processing and executive function, the $\mathrm{K} 2$ phenotype was distinguished by moderate-to-severe deficits in learning and memory retrieval, and impaired speed of processing and executive function. The last phenotype (K3) was characterized by an almost normal performance in most participants on most of the cognitive domains assessed. These results are in line with other studies $[5,8,9]$, except for the low impairment in attention.

The presence of cognitive alterations in different domains in ICU survivors might suggest different patterns of brain dysfunction which probably involve various pathophysiological mechanisms or pathways. More specifically, while speed of processing, executive functions and memory retrieval impairments are related to dysfunctions in subcortical areas and the frontal lobe, the presence of learning and memory storage problems points to alterations in the hippocampus and the medial temporal lobe.

Using the classical approach for cognitive impairment, almost half of the participants (47\%) showed moderateto-severe cognitive impairment 1 month after ICU discharge. This low incidence in comparison with other studies [2, 3, 7] may be related to the patients' clinical characteristics, given that our sample presented lower severity of illness and shorter duration of delirium during ICU stay than samples in other reports. Moreover, while pre-existing cognitive impairment was ruled out in our patients, in other studies it may have contributed to the overall cognitive impairment observed. Interestingly, when the results of the unsupervised learning machine method were compared with the classical approach, 86\% of the participants were accurately classified between the two categories of impaired and non-impaired cognition. Thus, the unsupervised learning machine method not only allowed detection of cognitive decline but also improved the classification of patients by identifying different patterns of cognitive impairment among ICU survivors.

The three cognitive phenotypes differed in terms of several demographic and clinical factors, a circumstance that may have had an impact on how the clusters were configured. Patients with the K1 phenotype had significantly fewer days of opioid treatment than patients in $\mathrm{K} 2$ and $\mathrm{K} 3$, and lower accumulated doses of opioids than K3. Participants in the $\mathrm{K} 2$ phenotype were mostly women, older and had more comorbidities than those in $\mathrm{K} 1$ and K3. Moreover, they presented lower accumulated doses 


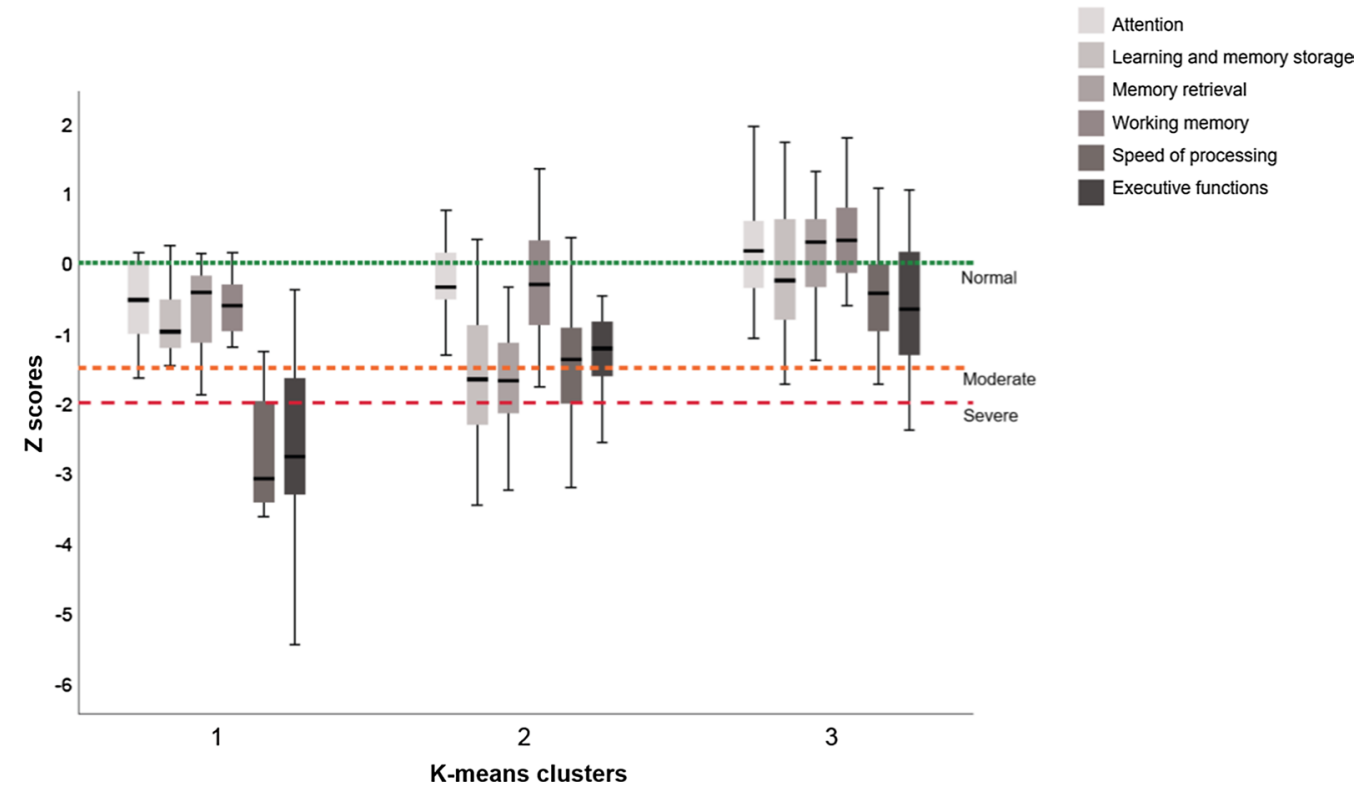

Fig. 2 Cognitive function distribution in the three patient clusters. The six cognitive indexes are represented according to each patient cluster. $Z$-scores between 0 and -1.5 are considered normal for the cognitive function in question, between -1.5 and -2 a moderate deficit, and below -2 a severe deficit

of sedative than K3. Finally, participants with the K3 phenotype showed higher levels of cognitive reserve than K1 and K2.

When the most cognitively affected phenotypes were combined (K1 and $\mathrm{K} 2$ ), the exploratory analysis of the predisposing and precipitating factors suggested that certain factors may play a more important role than others for the development of cognitive decline after ICU. Specifically, female gender, older age and a lower level of cognitive reserve were significantly associated with cognitive impairment.

Looking at these factors individually, we found that women were more likely to present cognitive impairment 1 month after ICU discharge. The role of gender in the cognitive impairment after ICU has not been specifically addressed, and the occasional references in the literature are contradictory $[5,34,35]$. Our results coincide with Habib et al. [35] in suggesting that female gender may be a risk factor for developing post-ICU cognitive impairment, at least early after ICU discharge. However, these conclusions should be interpreted with caution: although in healthy populations older women usually perform better in verbal memory tests than older men [36], normal aging itself entails cognitive deficits, especially memory and speed of processing [37]. Previous results for the impact of age on the cognitive status of ICU survivors are controversial $[3,4,9,25,34,35,38]$. Our results corroborate the notion that older critical care patients are more likely to present cognitive decline after critical illness.
However, we cannot rule out a relation between age and gender in our sample, since patients in phenotype K2 (deficits in memory, speed of processing and executive dysfunction) tended to be female, older and presented more comorbidities. If female patients are commonly older, and if aging affects cognitive status in women differently than in men, it may be that the impact of ICU stay on cognition in older critically ill patients also differs between genders.

In this study, patients in the phenotype with the best cognitive performance (K3) presented the highest level of cognitive reserve. Although the analysis is only exploratory, cognitive reserve was found to be a protective factor against cognitive alterations 1 month after ICU survival. Only one previous study [10] has included this concept as a predisposing factor for cognitive decline in ICU patients. Interestingly, cognitive reserve has also been identified as a protective factor for cognitive decline in healthy older adults $[39,40]$ and in a wide range of medical populations [41-43], including older patients with postsurgical delirium [44].

One of the phenotypes with cognitive impairment (K1) presented significantly fewer days with opioid treatment than the others. Although the ratio between days with opioids and days of ICU stay only reached a trend towards significance in the exploratory analysis, opioid treatment was the only precipitating factor that could be related to cognitive decline in our sample. It should be borne in mind that opioid treatment 


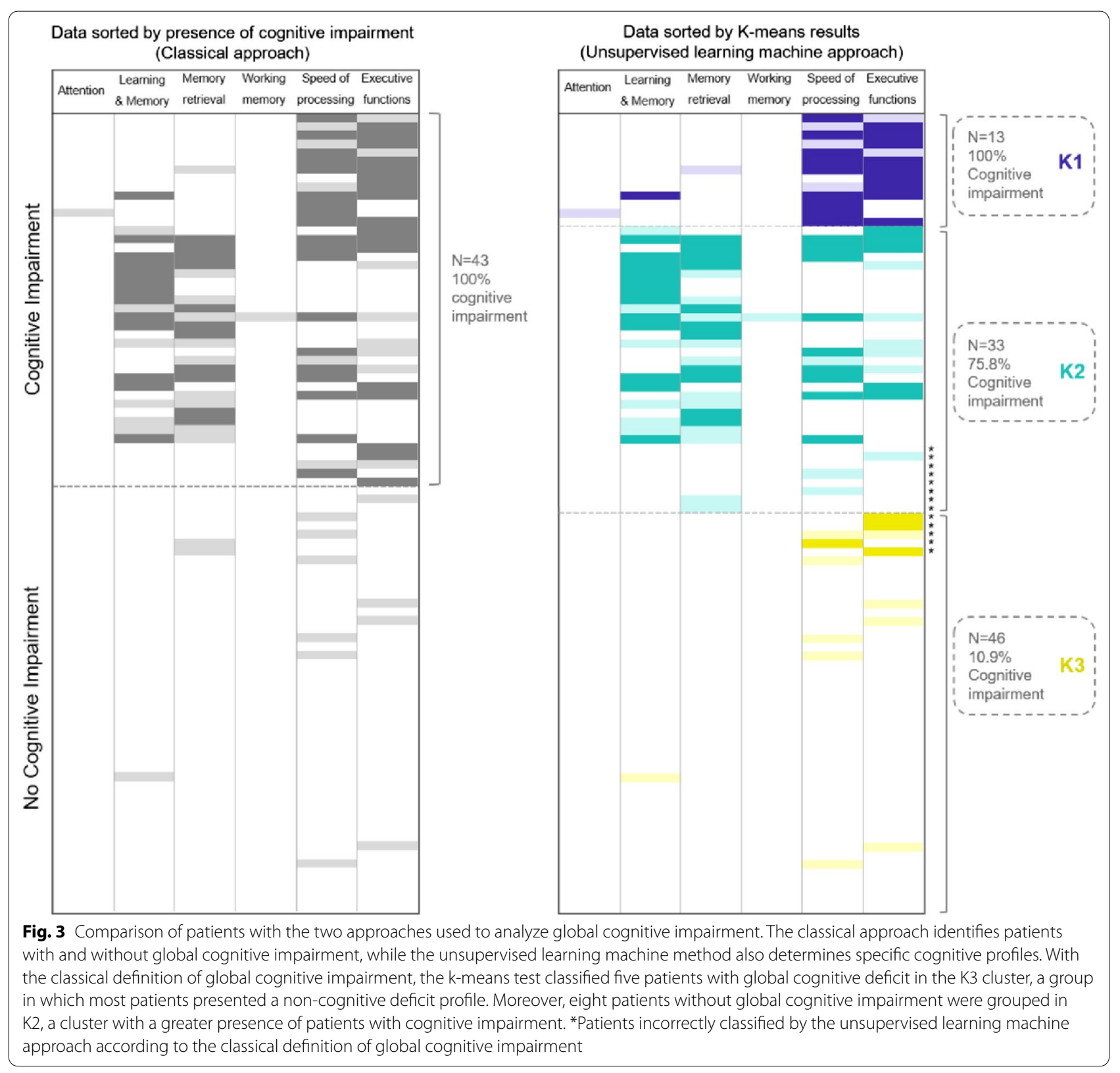

improves the welfare and comfort of critically ill patients, enhancing their emotional status. This emotional well-being related to the management of the analgesia and sedation during ICU stay may impact the cognitive status of survivors.

Duration of delirium was not related to cognitive impairment. This may have been due to the notably short duration of delirium in our patients and the low inter-subject variability; furthermore, our patients were assessed 1 month after ICU discharge, while in the other studies the impact of delirium on cognition was assessed at 3 or 12 months.
Although the analysis was only exploratory, our results suggested a higher burden of predisposing factors (such as gender, age and cognitive reserve) than precipitating factors in the specific cognitive impairment detected early after ICU discharge.

The current results should be confirmed in future studies with a higher number of participants. Nevertheless, our preliminary findings may serve as a starting-point for further research. Of particular interest is the evolution of the cognitive sequelae in the two phenotypes with cognitive impairment. Establishing how patients in $\mathrm{K} 1$ and $\mathrm{K} 2$ resolve (or maintain) their cognitive deficits might 
Table 3 Demographic and clinical characteristics of the sample according to cluster group

\begin{tabular}{|c|c|c|c|c|}
\hline Demographic and clinical variables & $\mathrm{K} 1(\mathrm{~N}=13)$ & $\mathrm{K} 2(\mathrm{~N}=33)$ & $\mathrm{K} 3(\mathrm{~N}=46)$ & $\mathrm{P}(<0.05)$ \\
\hline Age, years ${ }^{a, c}$ & $59(51.5-63.5)$ & $72(66-78)$ & $60(50-69)$ & $<0.001$ \\
\hline \multicolumn{5}{|l|}{ Gender (\%) } \\
\hline Female gender & $3(23.1)$ & $21(63.6)$ & $11(23.9)$ & 0.001 \\
\hline Cognitive reserve $e^{b, c}$ & $-0.07(-0.94$ to -0.05$)$ & $-0.11(-0.45$ to -0.23$)$ & $0.31(-0.08$ to 0.68$)$ & $<0.001$ \\
\hline Diagnosis (\%) & & & & 0.507 \\
\hline Medical & $12(92.3)$ & $27(81.8)$ & $35(76.1)$ & \\
\hline Surgical & $1(7.7)$ & $5(15.2)$ & $4(8.7)$ & \\
\hline Polytrauma & $0(0.00)$ & $1(3.0)$ & $7(15.2)$ & \\
\hline APACHE II at ICU admission, points & $15(12-18)$ & $18(15.5-22.5)$ & $17(12-20.25)$ & 0.082 \\
\hline SOFA at ICU admission, points & $8(5.5-10.5)$ & $7(4-10)$ & $7(5-9)$ & 0.719 \\
\hline SOFA slope & $-1.1(-1.8$ to -0.35$)$ & $-0.9(-1.5$ to -0.25$)$ & $-0.75(-1.4$ to -0.12$)$ & 0.536 \\
\hline Charlson Index at ICU admission ${ }^{a, c}$ & $3(2.5-4)$ & $5(3-6)$ & $3(1-4)$ & $<0.001$ \\
\hline Length of MV, days & $5(4.5-10)$ & $5(3-8)$ & $7(4-11)$ & 0.222 \\
\hline MV days ratio & $0.67(0.45-0.73)$ & $0.64(0.38-0.71)$ & $0.63(0.44-0.8)$ & 0.492 \\
\hline Length of delirium, days & $0(0-1)$ & $1(0-2)$ & $0(0-2)$ & 0.451 \\
\hline Delirium ratio & $0(0-0.12)$ & $0.08(0-0.22)$ & $0(0-0.10)$ & 0.367 \\
\hline Accumulated dose of sedatives ${ }^{c}$ & $4.29(0.29-16.38)$ & $1.35(0.35-6.20)$ & $3.85(1.92-10.62)$ & 0.050 \\
\hline Accumulated dose of opioids ${ }^{b}$ & $0.00(0.00-2.33)$ & $0.83(0.29-2.10)$ & $1.45(0.63-2.52)$ & 0.039 \\
\hline Days with sedatives & $4(1-7)$ & $3(1-6.5)$ & $4(3-7.25)$ & 0.178 \\
\hline Days with sedatives ratio & $0.44(0.13-0.64)$ & $0.28(0.12-0.47)$ & $0.40(0.22-0.60)$ & 0.163 \\
\hline Days with opioids ${ }^{a, b}$ & $0(0-5)$ & $4(2-7)$ & $5(3-9)$ & 0.016 \\
\hline Days with opioids ratio ${ }^{a, b}$ & $0.00(0.00-0.37)$ & $0.35(0.22-0.61)$ & $0.5(0.33-0.64)$ & 0.007 \\
\hline Length of ICU stay, days & $11(7-12.5)$ & $9(7-18.5)$ & $11(8-16.25)$ & 0.604 \\
\hline Length of hospital stay after ICU discharge, days & $15(9-30)$ & $17(11-49)$ & $17.50(9-31.5)$ & 0.591 \\
\hline
\end{tabular}

Data are expressed as $\mathrm{n}(\%)$ or median (IQR), as appropriate. IQR interquartile range, APACHE Acute Physiology and Chronic Health Evaluation, SOFA Sequential Organ Failure Assessment, $M V$ mechanical ventilation

a Significant difference between $\mathrm{K} 1$ versus $\mathrm{K} 2$

b Significant difference between $\mathrm{K} 1$ versus K3

c Significant difference between $\mathrm{K} 2$ versus K3

help to clarify the burden of predisposing factors in longterm cognitive decline in ICU survivors. Determining how brain changes associated with aging in both genders may be impacted by critical illness, and how cognitive reserve may decrease this impact, also deserves further investigation.

The main limitation of this study is the size of the sample obtained in one of the clusters generated by the $\mathrm{K}$-means clustering algorithm. This small size hampered the analysis of the role of the predisposing and precipitating factors in the three cognitive phenotypes in the ICU MV survivors. The two phenotypes that included most of their participants with cognitive impairment had to be combined in a single group in order to run the analysis. Nonetheless, the analysis was underpowered and it must be considered as exploratory. However, the strict selection of participants (with control of any previous cognitive impairment), and the careful statistical analysis vouch for the accuracy of our conclusions. The optimal interval for cognitive assessment may also be a limitation for performing comparisons with other studies, although it was appropriate for detecting the cognitive phenotype in the early stages of the recovery phase.

\section{Conclusions}

Three cognitive phenotypes were identified in the critically ill mechanically ventilated survivors 1 month after ICU discharge using the unsupervised machine learning K-means clustering algorithm. This approach improved the classical classification of patients by identifying different patterns of cognitive impairment among ICU survivors. Despite the exploratory nature of the analysis, female gender, older age and low cognitive reserve seemed to play relevant roles as predisposing factors for severe cognitive impairment in these patients. It is worth noting that the findings of the factors' analysis are statistically underpowered, and that further studies should be conducting to obtain definite conclusions. Thus, critical illness, together with the predisposing characteristics of each patient, might trigger 
different brain dysfunctions the mechanically ventilated patients at early stages of the ICU recovery.

\section{Supplementary information}

Supplementary information accompanies this paper at https://doi. org/10.1186/s13054-020-03334-2.

Additional file 1: This additional file contains Tables S1-S5, supplemental references and Figures S1-S3.

\section{Acknowledgements}

The authors thank Michael Maudsley for his invaluable support in editing the manuscript, and Carles Forné for his contribution to the statistical analysis.

\section{Authors' contributions}

SFG, CDH, CS, JLA, ARO, RF and LB designed the study; RM, LS and MRM performed the statistical analysis; GGF, CDH, SFG and GNV run the database and the eCRF; SFG, GNV, NB and MJ performed the neuropsychological assessments. All authors participated in the interpretation of the results. SFG, GNV and JFL drafted the manuscript; DJP and MJ provided psychological and neuropsychological expertise in designing the protocol. All authors read and approved the final manuscript.

\section{Funding}

This work was funded by projects PI13/02204 and PI16/01606, integrated in the Plan Nacional de R+D + I, and co-funded by the ISCIII Subdirección General de Evaluación y el Fondo Europeo de Desarrollo Regional (FEDER). CIBER Enfermedades Respiratorias, Fundació Parc Taulí-13PT, (Spain).

\section{Availability of data and materials}

The datasets used and analyzed during this study are available from the corresponding author on reasonable request.

\section{Ethics approval}

The institutional review boards of each participating ICU approved the protocol and the informed consent documentation.

\section{Consent for publication}

All participants consent for the publication of data generated in this study.

\section{Competing interests}

The authors declare that they have no competing interests.

\section{Author details}

${ }^{1}$ Critical Care Center, Parc Taulí Hospital Universitari, Fundació- I3PT, UAB, Sabadell, Spain. ${ }^{2}$ Centro de Investigación Biomédica En Red en Salud Mental (CIBERSAM), Instituto de Salud Carlos III, Madrid, Spain. ${ }^{3}$ Department of Clinical and Health Psychology, Universitat Autònoma de Barcelona, Bellaterra, Barcelona, Spain. ${ }^{4}$ Centro de Investigación Biomédica En Red en Enfermedades Respiratorias (CIBERES), Instituto de Salud Carlos III, Madrid, Spain. ${ }^{5}$ Mental Health Department, Fundació Althaia - Xarxa Assistencial I Universitaria, Manresa, Spain. ${ }^{6}$ Critical Care Center, Fundació Althai, Universitat Internacional de Catalunya, Manresa, Spain. ${ }^{7}$ Better Care S.L., Barcelona, Spain. ${ }^{8}$ Department of Medicine, Universitat de Barcelona, Barcelona, Spain. ${ }^{9}$ Neurology Department, Parc Taulí Hospital Universitari, I3PT, UAB, Sabadell, Spain. ${ }^{10}$ Departament of Basic Medical Sciences, Universitat de Lleida, Lleida, Spain. ${ }^{11}$ Health Services Research Network in Chronic Diseases (REDISSEC), Barcelona, Spain. ${ }^{12}$ Mental Health Department, Parc Taulí Hospital Universitari, I3PT, UAB, Sabadel, Spain. ${ }^{13}$ Department of Psychiatry and Forensic Medicine, Universitat Autònoma de Barcelona, Bellaterra, Barcelona, Spain.

Received: 22 April 2020 Accepted: 6 October 2020

Published online: 21 October 2020

\section{References}

1. Ehlenbach WJ, Hough CL, Crane PK, Haneuse SJPA, Carson SS, Curtis R, et al. Association between acute care and critical illness hospitalization and cognitive function in older adults. JAMA. 2010;303:763. https://doi. org/10.1001/jama.2010.167.

2. Girard TD, Jackson JC, Pandharipande PP, Pun BT, Thompson J, Ayumi SK, et al. Delirium as a predictor of long-term cognitive impairment in survivors of critical illness. Crit Care Med. 2010;38:1513. https://doi. org/10.1097/CCM.0b013e3181e47be1.

3. Pandharipande PP, Girard TD, Jackson JC, Morandi A, Thompson JL, Pun BT, et al. Long-term cognitive impairment after critical illness. N Engl J Med. 2013;369:1306. https://doi.org/10.1056/NEJMoa1301372.

4. Torgersen J, Hole JF, Kvåle R, Wentzel-Larsen T, Flaatten H. Cognitive impairments after critical illness. Acta Anaesthesiol Scand. 2011;55:1044. https://doi.org/10.1111/j.1399-6576.2011.02500.x.

5. Hopkins RO, Weaver LK, Collingridge D, Parkinson RB, Chan KJ, Orme JF. Two-year cognitive, emotional, and quality-of-life outcomes in acute respiratory distress syndrome. Am J Respir Crit Care Med. 2005;171:340. https://doi.org/10.1164/rccm.200406-7630C.

6. Iwashyna TJ, Ely EW, Smith DM, Langa KM. Long-term cognitive impairment and functional disability among survivors of severe sepsis. JAMA. 2010;304:1787. https://doi.org/10.1001/jama.2010.1553.

7. Jackson JC, Girard TD, Gordon SM, Thompson JL, Shintani AK, Thomason JWW, et al. Long-term cognitive and psychological outcomes in the awakening and breathing controlled trial. Am J Respir Crit Care Med. 2010;182:183. https://doi.org/10.1164/rccm.200903-0442OC.

8. Jackson JC, Hart RP, Gordon SM, Shintani A, Truman B, May L, et al. Six-month neuropsychological outcome of medical intensive care unit patients. Crit Care Med. 2003;31:1226. https://doi.org/10.1097/01. CCM.0000059996.30263.94.

9. Jones C, Griffiths RD, Slater T, Benjamin KS, Wilson S. Significant cognitive dysfunction in non-delirious patients identified during and persisting following critical illness. Intensive Care Med. 2006:32:923. https://doi. org/10.1007/s00134-006-0112-y.

10. Larson MJ, Weaver LK, Hopkins RO. Cognitive sequelae in acute respiratory distress syndrome patients with and without recall of the intensive care unit. J Int Neuropsychol Soc. 2007;13:595. https://doi.org/10.1017/ S1355617707070749.

11. Mikkelsen ME, Christie JD, Lanken PN, Biester RC, Thompson BT, Bellamy $\mathrm{SL}$, et al. The adult respiratory distress syndrome cognitive outcomes study. Am J Respir Crit Care Med. 2012;185:1307. https://doi.org/10.1164/ rccm.201111-20250C.

12. Schulte PJ, Warner DO, Martin DP, Deljou A, Mielke M, Knopman D, et al. Association between critical care admissions and cognitive trajectories in older adults. Crit Care Med. 2019;47:1116. https://doi.org/10.1097/ CCM.0000000000003829.

13. Guerra C, Linde-Zwirble WT, Wunsch H. Risk factors for dementia after critical illness in elderly Medicare beneficiaries. Crit Care. 2012;16:R233. https://doi.org/10.1186/cc11901.

14. Iwashyna TJ, Netzer G. The burdens of survivorship: an approach to thinking about long-term outcomes after critical illness. Semin Respir Crit Care Med. 2012;33:327. https://doi.org/10.1055/s-0032-1321982.

15. Langa KM, Chernew ME, Kabeto MU, Herzog AR, Ofstedal MB, Willis RJ, et al. National estimates of the quantity and cost of informal caregiving for the elderly with dementia. J Gen Intern Med. 2001;16:770. https://doi. org/10.1111/j.1525-1497.2001.10123.x

16. Rockwood K, Brown M, Merry H, Sketris I, Fisk J. Societal costs of vascular cognitive impairment in older adults. Stroke. 2002;33:1605. https://doi. org/10.1161/01.str.0000017878.85274.44.

17. Wolters AE, Slooter AJC, van der Kooi AW, van Dijk D. Cognitive impairment after intensive care unit admission: a systematic review. Intensive Care Med. 2013;39:376. https://doi.org/10.1007/s00134-012-2784-9.

18. Wilcox ME, Brummel NE, Archer K, Wesley EE, James J, Hopkins R. Cognitive dysfunction in ICU patients: risk factors, predictors, and rehabilitation interventions. Crit Care Med. 2013;41:S81. https://doi.org/10.1097/ cCM.0b013e3182a16946.

19. Fernandez-Gonzalo S, Turon M, De Haro C, Lopez-Aguilar J, Jodar M, Blanch L. Do sedation and analgesia contribute to long-term cognitive dysfunction in critical care survivors? Med intensiva. 2018;42:114. https:// doi.org/10.1016/j.medin.2017.06.010. 
20. Hopkins RO, Suchyta MR, Snow GL, Jephson Al, Weaver LK, Orme JF. Blood glucose dysregulation and cognitive outcome in ARDS survivors. Brain Inj. 2010;24:1478. https://doi.org/10.3109/02699052.2010.506861.

21. Duning T, van den Heuvel I, Dickmann A, Volker T, Wempe C, Reinholz J, et al. Hypoglycemia aggravates critical illness-induced neurocognitive dysfunction. Diabetes Care. 2010;33:639. https://doi.org/10.2337/ dc09-1740.

22. Sakusic A, Gajic O, Singh TD, O'Horo J, Jenkins G, Wilson G, et al. Risk factors for persistent cognitive impairment after critical illness. Nested Case-Control Study Crit Care Med. 2018;46:1977. https://doi.org/10.1097/ CCM.0000000000003395.

23. Davydow DS, Zatzick D, Hough CL, Katon WJ. In-hospital acute stress symptoms are associated with impairment in cognition 1 year after intensive care unit admission. Ann Am Thorac Soc. 2013;10:450. https://doi. org/10.1513/AnnalsATS.201303-0600C.

24. Gunther ML, Morandi A, Krauskopf E, Pandharipande P, Timothy GD, James JC, et al. The association between brain volumes, delirium duration, and cognitive outcomes in intensive care unit survivors: the VISIONS cohort magnetic resonance imaging study*. Crit Care Med. 2012;40:2022. https://doi.org/10.1097/CCM.0b013e318250acc0.

25. Hope AA, Morrison RS, Du Q, Wallenstein S, Nelson JE. Risk factors for long-term brain dysfunction after chronic critical illness. Ann Am Thorac Soc. 2013;10:315. https://doi.org/10.1513/AnnalsATS.201211-0990C.

26. van den Boogaard M, Schoonhoven L, Evers AWM, van der Hoeve JG, van Achterberg T, Peter P, et al. Delirium in critically ill patients: impact on long-term health-related quality of life and cognitive functioning. Crit Care Med. 2012:40:112. https://doi.org/10.1097/CCM.0b013e31822e9fc9.

27. Jackson JC, Archer KR, Bauer R, Abraham CM, Song Y, Greevey R, Guillamondegui $\mathrm{O}$, et al. A prospective investigation of long-term cognitive impairment and psychological distress in moderately versus severely injured trauma intensive care unit survivors without intracranial hemorrhage. J Trauma. 2011;71:860. https://doi.org/10.1097/TA.0b013e3182 151961.

28. Stern Y. Cognitive reserve in ageing and Alzheimer's disease. Lancet Neurol. 2012:11:1006. https://doi.org/10.1016/S1474-4422(12)70191-6.

29. Morales Gonzalez J, Gónzalez-Montalvo J, Del Ser QT, Bermejo PF. Validation of the S-IQCODE: the Spanish version of the informant questionnaire on cognitive decline in the elderly. Arch Neurobiol (Madr). 1992;55:262.

30. de Haro C, Magrans R, López-Aguilar J, Montanyà J, Lena E, Subirpa C, et al. Effects of sedatives and opioids on trigger and cycling asynchronies throughout mechanical ventilation: an observational study in a large dataset from critically ill patients. Crit Care. 2019;23:245. https://doi. org/10.1186/s13054-019-2531-5.

31. MacPherson SE, Healy C, Allerhand M, Spanò B, Tudor-Sfetea C, White M, et al. Cognitive reserve and cognitive performance of patients with focal frontal lesions. Neuropsychologia. 2017;96:19. https://doi.org/10.1016/j. neuropsychologia.2016.12.028.

32. Sanchez-Pinto LN, Luo Y, Churpek MM. Big data and data science in critical care. Chest. 2018;154:1239. https://doi.org/10.1016/j.chest .2018.04.037.
33. Livon D, Xie S, Eppig J, Wicas G, Lamar M, Lippa C, et al. The heterogeneity of mild cognitive impairment: A neuropsychological analysis. J Int Neuropsych Soc. 2010;16:84-93. https://doi.org/10.1017/S13556177099909 93.

34. Karnatovskaia LV, Schulte PJ, Philbrick KL, Johnson MM, Anderson BK, Gajic O, et al. Psychocognitive sequelae of critical illness and correlation with 3 months follow up. J Crit Care. 2019;52:166. https://doi. org/10.1016/j.jcrc.2019.04.028.

35. Habib S, Khan AR, Afridi MI, Saeed A, Jan AF, Amjad N. Frequency and predictors of cognitive decline in patients undergoing coronary artery bypass graft surgery. J Coll Physicians Surg Pak. 2014;24:543.

36. Munro CA, Winicki JM, Schretlen DJ, Gower EW, Turano KA, Muñoz B, et al. Sex differences in cognition in healthy elderly individuals. Neuropsychol Dev Cogn B Aging Neuropsychol Cogn. 2012;19:759. https://doi. org/10.1080/13825585.2012.690366.

37. Caselli RJ, Dueck AC, Locke DEC, Baxter LC. Sex-based memory advantages and cognitive aging: a challenge to the cognitive reserve construct? J Int Neuropsychol Soc. 2015;21:95. https://doi.org/10.1017/ S1355617715000016.

38. Sakusic A, O'Horo JC, Dziadzko M, Volha D, Ali R, Singh TD, et al. Potentially modifiable risk factors for long-term cognitive impairment after critical illness: a systematic review. Mayo Clin Proc. 2018:93:68. https://doi. org/10.1016/j.mayocp.2017.11.005.

39. Clare L, Wu Y-T, Teale JC, MacLeod C, Matthews F, Brayne C, et al. Potentially modifiable lifestyle factors, cognitive reserve, and cognitive function in later life: a cross-sectional study. PLOS Med. 2017;14:1-14. https://doi. org/10.1371/journal.pmed.1002259.

40. Roldán-Tapia MD, Cánovas R, León I, García-Garcia J. Cognitive vulnerability in aging may be modulated by education and reserve in healthy people. Front Aging Neurosci. 2017;9:1. https://doi.org/10.3389/fnagi .2017.00340.

41. Amoretti S, Cabrera B, Torrent C, Mezquida G, Lobo A, González-Pinto A, et al. Cognitive reserve as an outcome predictor: first-episode affective versus non-affective psychosis. Acta Psychiatr Scand. 2018;138:441. https ://doi.org/10.1111/acps.12949.

42. Lucero C, Campbell MC, Flores H, Maiti B, Perlmutter JS, Foster ER. Cognitive reserve and $\beta$-amyloid pathology in Parkinson disease. Parkinsonism Relat Disord. 2015;21:899. https://doi.org/10.1016/j.parkreldis.2015.05.020

43. Soldan A, Pettigrew C, Cai Q, Wang J, Wang MC, Moghekar A, et al. Cognitive reserve and long-term change in cognition in aging and preclinical Alzheimer's disease. Neurobiol Aging. 2017;60:164. https://doi. org/10.1016/j.neurobiolaging.2017.09.002.

44. Tow A, Holtzer R, Wang C, Sharan A, Kim SJ, Gladstein A, et al. Cognitive Reserve and Postoperative Delirium in Older Adults. J Am Geriatr Soc. 2016;64:1341. https://doi.org/10.1111/jgs.14130.

\section{Publisher's Note}

Springer Nature remains neutral with regard to jurisdictional claims in published maps and institutional affiliations.

\footnotetext{
Ready to submit your research? Choose BMC and benefit from:

- fast, convenient online submission

- thorough peer review by experienced researchers in your field

- rapid publication on acceptance

- support for research data, including large and complex data types

- gold Open Access which fosters wider collaboration and increased citations

- maximum visibility for your research: over $100 \mathrm{M}$ website views per year
}

At $\mathrm{BMC}$, research is always in progress.

Learn more biomedcentral.com/submissions 